\title{
HIV Status and High Risk Behavior of Men having Sex with Men
}

\author{
${ }^{1,2}$ Chandra Prakash Bhatt, ${ }^{2}$ Medha Sharma \\ ${ }^{1}$ Kathmandu Medical College, Sinamangal, Kathmandu, Nepal \\ ${ }^{2}$ Nobel College, Sinamangal, Kathmandu, Nepal
}

\begin{abstract}
Voluntary counseling and testing (VCT) of HIV is important intervention for the prevention of HIV infection. Aim of this study was to find out HIV status and high risk behavior of men having sex with men. This descriptive cross sectional study was conducted among men having sex with men (MSM) by administering structured questionnaires. The number of risk factors in a single individual ranged from one to seven out of eight. The mean risk factor was 3.38, with standard deviation 1.3. More than half (55.33\%) of them perceived at low risk, 33\% perceived themselves at high risk. Regarding HIV status of respondents, $8 \%$ were found to be positive. In the past 30 days the respondents had large number of sex partners; majorities of them $90 \%$ and $87.3 \%$ had 0-20 regular and casual sex partners but 9.8\% of MSM had 21-40 regular sex partners and 2.9\% had 81-100 casual sex partners respectively. Among the MSM 46.6\% were commercial sex worker, 35\% were sex drives and $18.4 \%$ were intravenous drug user. Majority of them (59.8\%) always used condom but $21.56 \%$ used sometime only. Some respondents $(3.9 \%)$ had sign of STIs and $5.8 \%$ had accident of needle injured. There are higher chances for transmission of HIV and other STDS among MSM. The role of VCT centre should be strengthen to awareness raising, isolate HIV positive cases treat them with antiretroviral drugs and counseling them to behavior change.
\end{abstract}

Key words: HIV, MSM, Risk factor

Corresponding address: Dr. Chandra Prakash Bhatt, Department of Microbiology, Kathmandu Medical College, Sinamangal Kathmandu Nepal. E-mail: drcpbhatt@gmail.com

\section{INTRODUCTION}

Men sex with men is out of norm among the population in Nepal. Nepal Supreme Court has ordered Nepal government to end discrimination against lesbian, gay, bisexual and transgender (LGBT) and to treat the same rights as other heterosexual citizens. Dance bars and restaurants in Nepal, especially in Kathmandu is the common location of commercial male to male sex. Both Nepalese and foreigners was seen in this places. ${ }^{1} \mathrm{VCT}$ is the process by which an individual undergoes counseling enabling him or her to make an informed choice about being tested for HIV. This decision must be entirely the choice of the individual and he or she must be assured that the process will be confidential. ${ }^{2}$ HIV voluntary counseling and testing has been shown to have a role in both HIV prevention and for people with HIV infection, as an entry point to care. In some countries where VCT services have been established there has also been a reluctance of people to attend for testing. This may be because of denial and of the stigma and discrimination that people who test sero-positive may face and the lack of perceived benefits of testing. ${ }^{3}$

The existence of males having sex with males in Nepal, their number, the extent of their sexual behaviors and its impact on the STI/HIV epidemic in the country is not known adequately. ${ }^{4}$ Men having sex with other men leads to greater health risks than men having sex with women. ${ }^{5}$ Human physiology makes it clear that the body was not designed to accommodate this activity. The rectum is significantly different from the vagina with regard to suitability for penetration by a penis. The vagina has natural lubricants and is supported by a network of muscles. It is composed of a mucus membrane with a multi-layer stratified squamous epithelium that allows it to endure friction without damage and to resist the immunological actions caused by semen and sperm. In comparison, the anus is a delicate mechanism of small muscles that comprise an exit-only passage. With repeated trauma, friction and stretching, the sphincter loses its tone and its ability to maintain a tight seal. Consequently, anal intercourse leads to leakage of fecal material that can easily become chronic. Anal intercourse also puts men at significant risk for anal cancer. Anal cancer is the result of infection with some subtypes of Human Papilloma Virus (HPV), which are known viral carcinogens. ${ }^{6}$ The prevalence of anal cancer among gay men is of great concern, those with AIDS, the rates are doubled. ${ }^{7}$ Men who have sex with men account for the lion's share of the increasing number of cases in America of sexually transmitted infections that are not generally spread through sexual contact. These diseases, with consequences that range from severe and even life-threatening to mere annoyances, include Hepatitis A, Epstein-Barr virus, ${ }^{9}$ Neisseria meningitides, ${ }^{10}$ shigellosis, salmonellosis, pediculosis, scabies and campylobacter. ${ }^{11}$ The U.S. Centers for Disease Control (CDC) identified a 1991 outbreak of Hepatitis A in New York City, in which 78\% of male respondents identified themselves as homosexual 
or bisexual. ${ }^{8}$ Salmonella is rarely associated with sexual activity except among gay men who have oral-anal and oralgenital contact following anal intercourse. ${ }^{12}$ The aim of this study was to determine HIV status and high risk behavior of man having sex with man in Kathmandu valley. This study provides basic information for the formulation of necessary polices and strategies for reducing risk behavior of MSM.

\section{MATERIALS AND METHODS}

The study is descriptive cross sectional. MSM who had come for post test counseling of VCT services in Kathmandu valley was the study population. The duration of the study was from June 2010 to December 2010. In this study MSM, those who had come for post test counseling in VCT centers in Kathmandu valley, able to understand Nepali language, more than 16 years old were included. Three different VCT centers in Kathmandu valley were taken in the study sites: 1. Parichaya Samaj, Lalitpur, 2. Blue Diamond Society, Bhaktapur and 3. Cruiseaids Nepal, Kathmandu. These sites are the sites providing VCT service to MSM in Kathmandu valley. The sample size of the study was 102 . According to United Nations General Assembly special session on HIV/ AIDS 2010 in Nepal the average number of people tested per VCT in 2009 were $348 .{ }^{13}$ The sampling was purposive, institution based sampling. A quantitative research approach was adopted in the study. The structured questionnaires were developed with reference to client information form. A structured questionnaire prepared in English and translated into Nepali language was the tool for data collection. The questionnaire was pretested on $10 \%$ of the population. The institution based sampling method was used to select the target population for the survey. After collection of data all the completed questionnaires were thoroughly checked and then coded in SPSS ver. 17.0. The statistical tools such as mean, median, standard deviation were used.

\section{RESULTS}

Table 1: Number of sex partners

\begin{tabular}{|c|c|c|}
\hline \multicolumn{3}{|c|}{$\begin{array}{c}\text { Number of sex partner in last 30 days. } \\
\text { (in percentage of each group) }\end{array}$} \\
\hline \multicolumn{3}{|c|}{ No. of regular sex partner } \\
\hline $0-20$ & Frequency & Percentage \\
\hline $21-40$ & 92 & 90.1 \\
\hline \multicolumn{3}{|c|}{ No. of casual sex partner } \\
\hline $0-20$ & Frequency & Percentage \\
\hline $21-40$ & 89 & 87.3 \\
\hline $41-60$ & 8 & 7.8 \\
\hline $61-80$ & 1 & 1 \\
\hline $81-100$ & 1 & 1 \\
\hline
\end{tabular}

In the past 30 days, the respondents had large number of sex partners. Majorities of them $90 \%$ and $87.3 \%$ had $0-20$ regular and casual sex partners respectively (Table 1).
Table 2: Risk group of the respondents

\begin{tabular}{|l|c|}
\hline \multicolumn{2}{|l|}{ Risk group of respondents (in percentage of each variable) } \\
\hline $\begin{array}{l}\text { Commercial sex worker (person selling sex for } \\
\text { economic benefit) }\end{array}$ & $46.6 \%$ \\
\hline Intravenous drug user & $18.4 \%$ \\
\hline Sex drive (person involving sex for enjoyment) & $35 \%$ \\
\hline Accident of needle injury & $5.8 \%$ \\
\hline STI (in past 3 months) & $3.9 \%$ \\
\hline
\end{tabular}

The majority of the respondents (46.6\%) were commercial sex workers followed by sex derives $35 \%$ and intravenous drug users $18.4 \%$ (Table 2).

Table 3: Number of risk factors incurred

\begin{tabular}{|c|c|c|}
\hline \multicolumn{3}{|c|}{ Personal risk factors } \\
\hline No. of risk factors & Frequency & Percentage \\
\hline 1.00 & 3.00 & 2.94 \\
\hline 2.00 & 24.00 & 23.53 \\
\hline 3.00 & 36.00 & 35.29 \\
\hline 4.00 & 21.00 & 20.59 \\
\hline 5.00 & 7.00 & 6.86 \\
\hline 6.00 & 10.00 & 9.80 \\
\hline 7.00 & 1.00 & 0.98 \\
\hline
\end{tabular}

The number of risk factors in a single individual was ranged from 1 to 7 out of 8 (Table 3). The mean of personal risk factor was 3.38, with standard deviation 1.3. The maximum number of respondents $(35.29 \%)$ had three risk factors. The personal risk factors included following characters of respondents: 1. Commercial sex workers. 2. Intravenous drug users. 3. Had sex without condom. 4. Sex derives (person involving sex for enjoyment). 5. Male having sex with male. 6. Multiple sex partners. 7. Accident of needle (pricked or stamped on a needle) 8 . Other risk factors please specify.

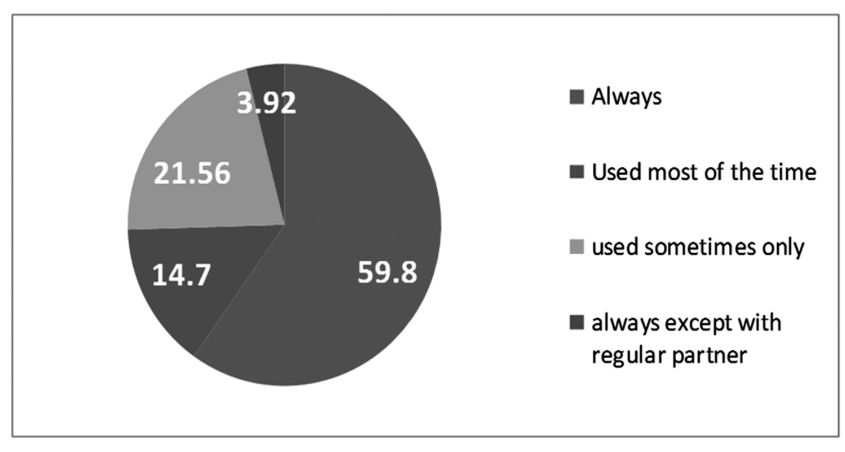

Figure 1: Condom use behavior of respondents

Condom use behavior of respondents, $59.8 \%$ of respondents have always used condom but $21.56 \%$ of respondents have used condom sometime only. Fig. 1 


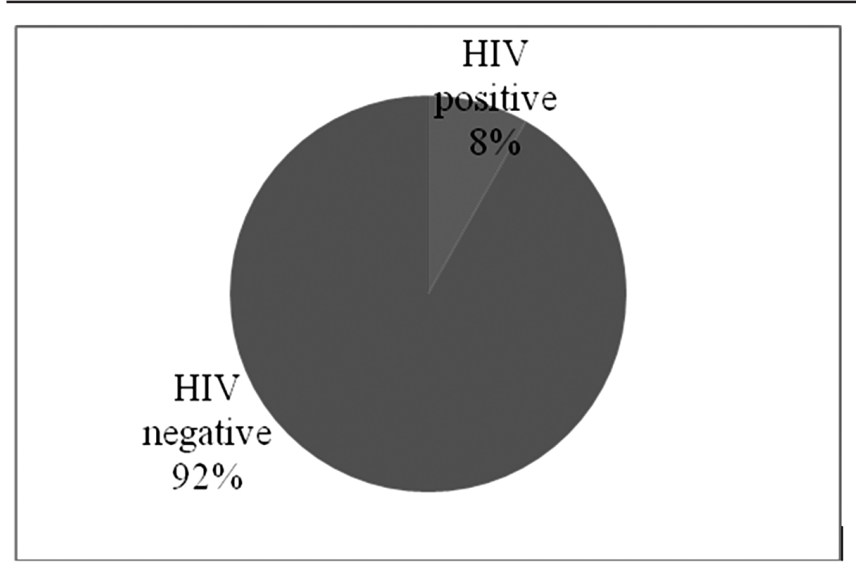

Figure 2: HIV status of the respondents

HIV status of the respondents, $8 \%$ of the respondents were found to be HIV positive. Figure 2

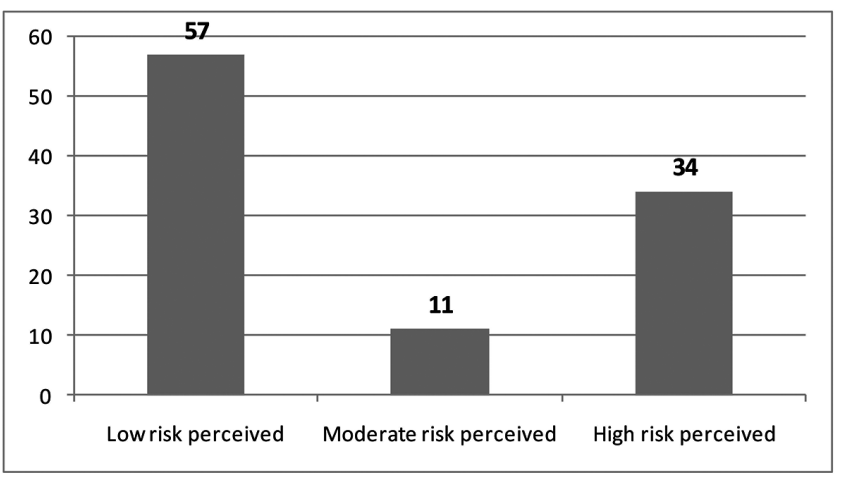

Figure 3: Self risk perception of the respondents towards contracting HIV or other STIs

Self risk perception of the respondents, more than half $(55.33 \%)$ of the respondents perceived themselves at low risk, but $33 \%$ perceived themselves at high risk (Figure 3).

\section{DISCUSSION}

This study provides basic information for the formulation of necessary polices and strategies for reducing risk behavior of MSM. The greater incidence of physical and mental health problems among gays and lesbians has serious consequences for length of life. While many are aware of the death toll from AIDS, there has been little public attention given to the magnitude of the lost years of life. Unhealthy sexual behaviors occur among both heterosexuals and homosexuals. Medical and social science evidence indicate that homosexual behavior is uniformly unhealthy. Although both male and female homosexual practices lead to increases in Sexually Transmitted Diseases.

The finding of this study showed that, past 30 days, the respondents had large number of sex partners. Majorities of them (90\%) had 0-20 regular sex partners and 87.3\% had 0-20 casual sex partners. The $9.8 \%$ of MSM had 21-40 regular sex partners and 2.9\% had 81-100 casual sex partners. Men having sex with other men leads to greater health risks than men having sex with women not only because of promiscuity but also because of the nature of sex among men. ${ }^{5}$ Similar study conducted in Mumbai showed that majorities (76.6\%) of sexual partners were casuals, $4.4 \%$ were regular and $20 \%$ were both. An analysis of various kinds of sexual partners, most of the MSM performs sex with casual partners. ${ }^{14}$ The Dutch study find a high rate of psychiatric disease associated with same-sex sex. ${ }^{15}$ The ideal of sexual activity being limited to marriage, always defined as male-female, has been a fence erected in all civilizations around the globe. ${ }^{16}$ Depression and drug abuse can lead to reckless sexual behavior, even among those who are most likely to understand the deadly risks. Multiple studies have identified high rates of psychiatric illness, including depression, drug abuse and suicide attempt, among self professed gays and lesbians. ${ }^{17}$ This study suggested that number of sex partners of MSM had very high and government should provide alternative job for commercial sex worker and VCT centre should be counseling them to change their behavior.

The result of this study showed that $18.4 \%$ of respondents were intravenous drug users (IDUs). Hepatitis viruses and HIV are transmitted by sexual as well blood borne route. Sexual transmission of HBV occurs everywhere. The risk of transmission by heterosexual and homosexual contact increases with the number of partners and the duration of such relationships.

Patients were asked about their self risk perception towards contracting HIV and STI. Among them only 33\% were perceived themselves at high risk but majority of them (46.6\%) were CSWs, $21.5 \%$ used condom sometime only and mean personal risk factor was 3.38. These groups are high risk groups for the transmission of STIs and AIDS. STIs and AIDS have higher chances of transmission to sex workers which are known as vulnerable groups. Study conducted by Mishra and Sharma showed that the use of condom is very low at the higher age group (52\%) as compared to young ones (78\%). Among those having sex with causal partners, with majority of the cases where the sexual history of the partners is hardly known to the respondents. ${ }^{14}$ The most alarming picture is that they did not use condom regularly, majority of them were commercial sex worker and number of sexual partners were very high, in this situation their risk perception is under estimated. This suggests that more awareness should be given to respondents on regular use of condom and importance of condom in anal sex.

As far as their sexual health problems are concern, 3.9\% of the respondents had sign of sexually transmitted infection. Similar study conducted in Mumbai reported that one-fifth of them reported to suffered from one or other sexually transmitted infections during last 12 months. Most of them did not like to speak out their anal problems to the service providers. ${ }^{14}$ The presence of STD is a marker of high risk behavior for HIV infection. STDs are biological co-factors of HIV transmission. The presence of a genital ulcer caused by chancroid or harpes increases ones risk of HIV infection 1-12 folds and the risk increases 3-4 folds where gonorrhea or chlamydia is present. ${ }^{18}$ 
The finding of this study showed that $8 \%$ of MSM was found to be HIV positive. Study conducted in Mumbai found higher than this study, $21 \%$ of MSM was found to be HIV positive. ${ }^{14}$ HIV is clearly a major cause of premature death and most causes are the result of sexual transmission. A number of studies showed an exceptional increase of HIV infection among commercial sex workers in India and Thailand. About $44 \%$ of lower class prostitutes of Chiang Mai, Thailand and $35 \%$ prostitutes of Bombay, India are infected with HIV. ${ }^{19}$ Study conducted by CDC 2001 reported that, nearly $64 \%$ of men with AIDS were men who have had sex with men. ${ }^{20}$ An epidemiological study from Vancouver, Canada between 1987 and 1992 for AIDS-related deaths reveals that male homosexual or bisexual practitioners lost up to 20 years of life expectancy. As per medical science, the chances of transmitting virus are more in anal sex than in peno-vaginal sex since the tissues inside the rectum are more flimsy. So, from all the angles, it shows that MSM are quite vulnerable to acquire STIs and HIV and infecting others. Therefore there is a need for government and nongovernmental organization to support VCT centre for treatment of HIV positive cases by antiretroviral drugs. The study was conducted in Kathmandu valley, among MSMs, risk is not compared with other group and sample size of this study is small. It is therefore recommended that a large sample size that would cover rural and urban area of Nepal should be considered in further studies.

\section{CONCLUSION}

The findings of this study showed that $8 \%$ of MSM was found to be HIV positive. Their sexual partners for past 30 days were very high $9.8 \%$ of MSM had 21-40 regular sex partners and $2.9 \%$ had $81-100$ casual sex partners, $21.56 \%$ of them used condom sometime only and mean risk factor was 3.38. There are higher chances for transmission of HIV and other STD among MSM. The role of VCT centre should be strengthen to awareness raising specifically about transmission of HIV through anal sex, importance of condoms for anal sex, isolate HIV positive cases, treat them with antiretroviral drugs and counseling them to behavior change. If preventive methods are not taken immediately it may be difficult to control the spread of HIV and STI among MSM.

\section{REFERENCES}

1. Karki S. HIV/AIDS situation in Nepal: Transition to women. Department of Medical and Health Sciences, Linköping University Sweden. 2006.

2. Baggaley R. Voluntary counseling and testing (VCT). Paper for the UNAIDS expert panel on HIV testing in United Nations peacekeeping operations. New York. Sept, 2001; 17-18.

3. Olsson P, Darj E, Britta E, Konde J, Eva B. Uganda: Responses to VCT for HIV among young people in Kampala, Uganda. AJAR. 2007.

4. IBBS. Integrated bio- behavioral survey. FHI and USAID. 2005.

5. The Gay and Lesbian Medical Association (GLMA) recently published a press release entitled Ten things gay men should discuss with their health care providers. July 17,2002. www.glma.org/news/ releases/n02071710gaythings.html.

6. Melbye M, Rabkin C, Frisch M, Biggar RJ. Changing patterns of anal cancer incidence in the United States, $1940-1989$. Am. J. Epidemiol. 1994; 139:772-80.

7. Goedert J, Coté T, Virgo P, Scoppa S, Kingma D, Gail M, et.al., AIDS-Cancer match study group. Spectrum of AIDSassociated malignant disorders. The Lancet. 1998; 351:1833-39.

8. Morbidity and Mortality Weekly Report Hepatitis A among homosexual men- United States, Canada, and Australia. Morbidity and Mortality Weekly Report, CDC. 1992; 41(09):155:161-64.

9. Naher H, Lenhard B, Wilms J, Nickel P. Detection of Epstein-Barr virus DNA in anal scrapings from HIV-positive homosexual men. Archives of Dermatological Research. 1995; 287(6):608- 11.

10. Carlson BL, Fiumara NJ, Kelly JR, McCormack WM. Isolation of Neisseria meningitidis from anogenital specimens from homosexual men. Sexually Transmitted Diseases. 1980; 7(2):71-73.

11. Paulet P, Stoffels G. Sexually-transmissible anorectal diseases. Revue Medicale Bruxelles. 1989; 10(8):327-34.

12. Thorpe CM, Keutsch GT. Enteric bacterial pathogens: Shigella, Salmonella, Campylobacter in K. K. Holmes, P. A. Mardh, (Eds.), Sexually Transmitted Diseases (3rd edition), New York: McGraw-Hill Health Professionals Division. $1999 ; 549$.

13. Country Progress Report Nepal. United Nations General Assembly special session on HIV/AIDS. UNGASS Country Progress Report Nepal. 2010; pp 1-77.

14. Mishra AK, Sharma AK. Redefining vulnerabilities: A study of man having sex with man in the wake of HIV epidemic in Mumbai, India. Paper presented into Annual Meeting of Population Association of America during 29 March- 31 March 2007.

15. Theo GM, Sandfort, Ron de Graff, Rob VB, Paul Schnabel. Same-sex sexual behavior and psychiatric disorders. Archives of General Psychiatry. 2001; 58(1): 85-91.

16. William N. Eskridge, Jr. The case for same-sex marriage, chapter 2, New York: The Free Press. 1996.

17. Mubarak SD. The gay community's new epidemic. Daily News. June 5, 2000; www.gaywired.com

18. Buve A, Laga M, Piot P. Sexually transmitted diseases. Health Policy Planning. 1993; 8(3):277-81.

19. Gazi EA. Awareness about AIDS and its preventive measures among sex workers of Banisanta at Mongla Port, Bagerhat (Masters Thesis). 1998; 1-1.

20. Basic Statistics, CDC-Division of HIV/AIDS Prevention. June 2001, www.cdc.gov/hiv/stats.htm. 